\title{
Choosing between pathogenicity and saprophytism: A case study from Rhizactonia solani, a potato pathogen
}

\author{
Manmathan $\mathrm{HK}^{1}$, Rioux $\mathrm{R}^{2}$ and Tavantzis $\mathrm{S}^{3}$ \\ 1 Department of Soil and Crop Sciences, Colorado State University, Fort Collins, CO 80523 \\ ${ }_{2}$ NewLeaf Symbiotics, BRDG Park, St. Louis, Missouri, United States of America \\ 3 School of Biology and Ecology, University of Maine, 5735 Hitchner Hall, Orono, ME 044695735
}

Manmathan HK, Rioux R and Tavantzis S 2015 - Choosing between pathogenicity and saprophytism: A case study from Rhizactonia solani, a potato pathogen. Mycosphere 6(4), 463-479, Doi 10.5943/mycosphere/6/4/8

\begin{abstract}
The basidiomycetous fungus Rhizoctonia solani is ubiquitous in the soil, can survive in soil as a saprophytic pathogen as well as infect the roots/ tubers and lower stems of plants. The virulent isolate of $R$. Solani anastomosis group 3, Rhs 1AP, causes black scurf disease of potato. Rhs 1AP shows reduced virulence in the presence of quinic acid, a phenolic compound from composted plant materials. To identify molecular mechanisms associated with quinic acid induced hypovirulence, a subtracted cDNA library was constructed from Rhs 1AP that had been made hypovirulent by the application of exogenous quinic acid in the presence of the potato host. Trends in the transcriptome indicated that quinic acid interferes with overall metabolic processes of fungal-plant interactions resulting in drastic changes in nitrogen and carbon metabolism, protein recycling, energy metabolism and down regulation of pathogenesis related genes. In addition, expression of genes associated with glyoxylate metabolism, and those linked to oxalate degradation were up regulated. These results provide an initial account of the molecular basis of quinic acid induced hypovirulence in $R$. solani in potato system.
\end{abstract}

Key words - black scurf - candidate genes - fungi - hypovirulence - quinic acid

\section{Introduction}

Rhizoctonia solani is a soil-borne basidiomycetous species complex that includes pathogens of many crop plants, mutualists of orchids and mosses, and saprophytes that cause decay of organic matter (Zheng et al. 2013). The $R$. solani species complex is the anamorph of the basidiomycete Thanatephorus cucumeris, which consists of at least 13 anastomosis groups (AG) (Carling 1996). AG3 is the major causative agent of Rhizoctonia disease of potato (Solanum tuberosum) (Bandy et al. 1988). Although this pathogen causes serious crop losses, no effective control strategy is currently available (Larkin \& Griffin 2007, Bernard et al. 2014).

Previous studies from our research group have shown that quinic acid (QA) brings about a dramatic reduction in the pathogenic capacity of the highly virulent isolate Rhs $1 \mathrm{AP}$, which is isogenic 
to nonvirulent isolate Rhs 1A1 (Liu et al. 2003a). This QA induced attenuation of virulence (QA induced hypovirulence) has important ramifications regarding the management of numerous diseases caused by $R$. solani on major crops around the world. QA is one of the most prevalent ( 2 to $10 \%$ of dry mass) phenolic compounds in composted plant materials (Leuschner et al. 1995), and can be utilized as the sole carbon source by soil microbial communities (Garland \& Mills, 1991), with the potential to have significant impact on soil biochemistry, microbiology, and ecology. It appears that QA has a regulatory effect on Rhs $1 \mathrm{AP}$, since the QA induced hypovirulence could not be overturned by chorismate. Chorismate is an end product of shikimic acid pathway (SHK pathway), which dramatically enhances the virulence of Rhs 1AP (Liu et al. 2003b). These hypovirulence mechanisms (constitutive and QA induced) have been used in a complementary manner to manage rhizoctonia disease of potato in an environmental friendly, sustainable crop production system (Bandy \& Tavantzis, 1990, Larkin et al. 2011), and have the potential to be used with many other major crops worldwide.

We report here the results of our efforts to utilize transcriptomic strategies to identify and characterize QA induced metabolic events in the virulent isolate Rhs1AP, which becomes o hypovirulent when treated with exogenous QA in the presence of sprouted potato tubers. Results of semi global transcriptome analysis established new evidence supporting the occurrence of a QA induced switch in carbon source in spite of the availability of host plant derived nutrients. Hypovirulence induction by QA brings about a shift in nitrogen and carbon metabolism, protein recycling, and active energy metabolism involving alternate carbon sources (other than glucose), in a manner similar but not identical to QA induced effects observed in the non pathogenic ascomycete Neurospora crassa (Logan et al. 2007). We also discuss the significance of the current findings within the context of pathogenesis, saprophytism and mutualism in plant associated fungi.

\section{Materials \& Methods}

\section{Fungal cultures and media}

Vogel's minimal salts solution (Davis \& deSerres 1970) containing $20 \mathrm{mM}$ glucose is referred to as liquid 'glucose minimal media.' Similarly, Vogel's minimal salts solution containing either quinic acid $(26 \mathrm{mM})$ or glycerol $(20 \mathrm{mM})$ as a sole carbon source is referred to as liquid 'QA minimal media' or liquid 'glycerol minimal media' (Lamb et al. 1992). QA induced or control mycelial cultures of $R$. solani isolates Rhs $1 \mathrm{AP}$ and Rhs $1 \mathrm{~A} 1$ were prepared as described previously (Liu et al. 2003a \& 2003b).

\section{Library subtraction and EST analysis}

EST library resulted from the suppression subtractive hybridization described in an earlier report by our research group (Lakshman et al. 2006) was used in this study. The driver cDNA was prepared from mycelia of the virulent isolate Rhs 1AP collected 18 hours post QA induction with QA $(5.6 \mathrm{mM})$ in the presence of sprouted potatoes. The tester cDNA was prepared from mycelia grown in the same manner as the driver but treated with water instead of QA. The SSH was performed using the Clontech PCR Select cDNA Subtraction Kit (BD Biosciences Clontech, Palo Alto, CA 94303, USA) according to manufacturer's procedure. Normalization of cDNA was checked with the BD Advantage 2 PCR enzyme kit (BD Biosciences Clontech) and primers specific for the $R$. solani (AG3) glyceraldehyde 3 phosphate dehydrogenase (G3PDH) (GeneBank Accession No. AF339929) and the $R$. solani (AG3) $\beta$ tubulin gene sequence (GeneBank Accession No. FJ392714). Subtracted cDNAs were cloned into a plasmid vectors using the TOPO ${ }^{\circledR}$ XL PCR Cloning Kit (Invitrogen, Carlsbad, USA) according the manufacturer's instructions. Plasmid DNA was isolated from a total of 713 randomly picked recombinant (white) colonies using the QIAprep Spin Miniprep Kit (Qiagen, Valencia, CA). The cDNA inserts were sequenced in both directions using M13 forward and reverse 
primers flanking the cDNA cloning site. Sequencing was performed by the University of Maine DNA Sequencing Facility (http://www2.umaine.edu/dnaseq/).

\section{Quality control and analysis of the EST library}

Background sequences from potential bacterial contamination, mitochondria, adapters, rRNA genes and other extraneous sequences of phage genomic origin were removed by 'webtraceminer' (http://www.coniferdb.org/software/wtm1.2/), using the NCBI UniVec database as reference. ESTs with long poly(A) tails and those with more than $3 \%$ ambiguous base reads were also eliminated, generating a total of 514 bona fide sequence tags. The total EST population (redundant tags) was analyzed by BlastX and BlastN against the UNI PROT_TREMBL databases (http://www.pir.uniprot.org) to provide an initial assessment of redundancy and homology. The total redundant EST set was analyzed for gene ontology (GO) by Blast2GO and KAAS (KEGG Automatic Annotation Server) (Moriya et al.2007) at a threshold e value of $10^{3}$.

Total content and representation of the EST library was evaluated by assembling the redundant tags into contigs using the CAP3 Assembler (Huang \& Madan $1999 \mathrm{http} / / \mathrm{pbil}$.univ lyon1.fr/cap3.php;). Tags were clustered through the overlapping sequences with corresponding quality scores for each resulting contig and singleton. Singletons and the consensus sequences for each contig were evaluated for similarities by BlastX and BlastN with the NCBI non redundant database as well as the UniPROT and UniPROT_TREMBL databases (http://www.pir.uniprot.org). Unigene sequences with low E values (E-value $\leq 1 \mathrm{e}-3$ ) were reanalyzed using PSI Blast (Altschul et al. 1997). Contigs that were ambiguously classified based on BLAST results, were blasted on the basis of the information provided by individual members of a particular contig (singletons). ESTs and contigs with ambiguous classifications or annotations were aligned with the draft genome sequence of the $R$. solani isolate AG3 Rhs 1AP (http://www.rsolani.org ) using BioEdit v7.0.9 (Hall 2004). Open reading frames within the genomic loci defined by the anchored ESTs were predicted using the Hidden Markov Model based $a b$ initio gene structure prediction software available from FGENESH (Solovyev et al. 2006). Phylogenetically related basidiomycete Coprinopsis cinerea was used as the background model. These predicted genes were reassessed in relation to their BlastX and BlastN E values.

ESTs were classified by gene ontology (GO) Blast2GO gene annotation software (Conesa et al. 2005 ) at a threshold $P$ value of 0.05 . Results were further compared with the annotation by the Kyoto Encyclopedia of Genes and Genomes (KEGG) (http://www.genome.jp/tools/kaas/). The output includes KEGG Ontology (KO) assignments and automatically generated biochemical pathways. The sequences were also submitted for analysis to Broad Institute's Fungal Genome Initiative site (http://www.broadinstitute.org/science/projects/fungal genome initiative/fungal genome initiative) that includes only fungal genomes. Additional manual annotation, literature searches and PSI Blast results were used to increase the resolution of the automated annotation as necessary. Total redundant ESTs were aligned with the unigene set prior to purging of redundant genes using the BLAST algorithm to evaluate relative transcription abundance. The cutoff for identity of the aligned ESTs to each unigene was set at $\mathrm{e} \leq 10^{3}$.

\section{Gene expression analysis by real time quantitative PCR (qRT PCR)}

For the analysis of QA induced gene expression, fungal mycelia tissues that had been thoroughly rinsed with minimal media were resuspended in $150 \mathrm{ml}$ of glycerol minimal media in 0.47 liter Mason jars for 2 hours in the presence of sprouted (3 to $5 \mathrm{~cm}$ long sprouts) whole potato tubers, which occupied approximately $80 \%$ of the media volume. QA $(\mathrm{pH} 6.0)$ was then added to a final concentration of $5.2 \mathrm{mM}$ as described by Lamb et al. (1992). As control experiments, fungal mycelia were resuspended in glycerol minimal media without QA on sprouted potato tubers. QA treated and control mycelia were incubated on a gyratory shaker $(250 \mathrm{rpm})$ at room temperature for $0,0.5,3,8,18$ and $36 \mathrm{hrs}$. Zero time samples were from control mycelia treated with water in the presence of 
sprouted potatoes. Mycelial cultures were harvested on a sterilized Büchner funnel as described by Liu et al. (2003a), frozen in liquid nitrogen, and stored at $80^{\circ} \mathrm{C}$ until use.

We compared relative transcription levels (RTL) of selected candidate genes identified from the QA induced EST library of AG3 with those of genes expressed by the $R$. solani AG3 potato, and $R$. solani (AG1 IA) rice patho-systems (Rioux et al. 2011). The pattern of expression of putative pathogenesis related genes of $R$. solani AG3 was expected to contrast that of the transcriptome associated with the QA induced hypovirulence. Two randomly selected AG3 homologues, identified by aligning AG1 1A ESTs to the Rhs 1AP (AG3) genomic sequence draft (http://www.rsolani.org/), were selected for qRT PCR expression analysis as a contrast to the QA induced genes. The AG3 gene homologues selected were Pro41 and an F box domain containing protein (Sec72) (Rioux et al. 2011), which have been shown to have roles in fungal pathogenesis (Nowrousian et al. 2007, Soanes et al. 2008). Expression of the above two genes was checked $18 \mathrm{hrs}$ post QA induction for two reasons: 1) the SSH library had been constructed using mycelia harvested $18 \mathrm{hrs}$ after QA induction, and 2) all 9 genes associated with QA induced hypovirulence were overexpressed at $18 \mathrm{hrs}$ post induction as compared to the control housekeeping genes (Fig.1) .

Quantitative real time PCR (qRT PCR) was performed using the MyiQ Single Color Real Time PCR Detection System (Bio Rad Laboratories, Hercules, CA) to analyze the expression of eleven candidate genes. Nine of the eleven candidate genes included in the expression profiling experiments were from the QA treated Rhs 1AP (AG3) subtracted EST library or expected to be induced by QA, and two were putative pathogenesis related AG3 genes expressed in potato during infection (Rioux et al. 2011). The candidate genes examined from QA treated Rhs 1AP (AG3) subtracted EST library included: 1) two genes from the QUT pathway, QUTA (QUT pathway activator) and QUTD (QA transporter), 2) two genes from the SHK pathway, AROM and EPSP (5 enolpyruvylshikimate 3 phosphate synthase) and, 3) a group that included a Thi $J$ like gene (represented by contig C1), formate dehydrogenase (FDH; represented by contig C41), an RTA1 like gene (represented by contig C45), permease (represented by contig C36) and a SSD1 like gene (represented by contig C12). Three of the five genes in the $3^{\text {rd }}$ group $(C 1, C 45$, and C12) were represented by the highest number of ESTs in the SSH library. All eleven genes were verified to be present on the genomic draft sequence of $R$. solani (AG3) both in silico (http://www.rsolani.org/) and by PCR using gene specific primers (see below; Table 1).

Total RNA was extracted from duplicate samples of two independent experiments; control and QA treated Rhs 1AP (in the presence of sprouted potato tubers) at $0,0.5,3,8,18$ and $36 \mathrm{hr}$ after treatment. First strand cDNA was synthesized from $1 \mu \mathrm{g}$ of DNase I treated RNA using the Transcriptor First Strand cDNA Synthesis Kit (Roche Applied Science, Indianapolis, USA). Real time PCR was performed using a reaction cocktail containing $0.2 \mu \mathrm{l}$ of the reverse transcription reaction, 10 $\mu 1$ of the $2 X$ ABsolute ${ }^{\mathrm{TM}}$ QPCR SYBR ${ }^{\circledR}$ Green Mix (Thermo Fisher Scientific, Rockford, IL, USA), and forward and reverse primers $(0.5 \mu \mathrm{M})$ at a final volume of $20 \mu \mathrm{l}$. Gene specific primers were designed to generate an amplicon of 149 to $220 \mathrm{bp}$ (Table 1). Primers were selected from exonic regions predicted by FGENESH in order to avoid amplification of potentially contaminating genomic DNA. Primer specificity was checked by PCR on pooled infection bioassay cDNA samples using GoTaq ${ }^{\circledR}$ Green Master Mix (Promega, Madison, WI) and an Eppendorf Mastercycler Gradient (Eppendorf North American, Hauppauge, NY). Standard gel electrophoresis using a 2\% TBE gel was used to check for a single product of the correct size. PCR products were then cleaned using the Qiaquick PCR Purification Kit (Qiagen Inc., Valencia, CA) according to the manufacturer's instructions and sequenced (University of Maine DNA Sequencing, Orono, ME, $\mathrm{http}: / / \mathrm{www} 2 . u m a i n e . e d u / d n a s e q /)$. Sequences were compared against the $R$. solani genome database to ensure the identity of the PCR products. Eleven primer pairs, for nine QA induced genes and two putative pathogenesis related genes passed these stringency checks and were used for qRT PCR analysis. 
Cycling for qRT PCR was performed as follows: 1) Initial denaturation at $95{ }^{\circ} \mathrm{C}$ for $15 \mathrm{~min}$; 2) Cycle denaturation at $95{ }^{\circ} \mathrm{C}$ for $15 \mathrm{sec}$; 3) Primer annealing at $60{ }^{\circ} \mathrm{C}$ for $30 \mathrm{sec}$; and 4) Extension at 72 ${ }^{\circ} \mathrm{C}$ for $30 \mathrm{sec}$. Amplification was performed for 40 cycles. Each candidate gene was profiled with three technical replicates. Expression values of the candidate genes were normalized relative to the constitutively expressed $\beta$ tubulin (BT) gene. Relative expression values were calculated as $2^{-\Delta \Delta} \mathrm{Ct}$, where ${ }^{\Delta \Delta} \mathrm{Ct}$ (gene of interest) $=$ Avg. ${ }^{\Delta} \mathrm{Ct}$ (gene of interest) - Avg. ${ }^{\Delta} \mathrm{Ct}$ (BT) (Livak \& Schmittgen 2001). Repetition of the expression analysis using the Pfaffl method (Pfaffl 2001) revealed similar trends in expression to those obtained with the Livak method. For an understanding of the expression pattern of the QA induced genes, a hierarchical clustering was done using the MultiExperiment Viewer (MEV) v4.6 software package (Saeed et al. 2006). Pearson's distance matrix was used to build the clusters.

Table 1 Target specific primers used for real- time quantitative RT- PCR

\begin{tabular}{|c|c|c|c|c|}
\hline $\begin{array}{l}\text { Primer } \\
\text { name }\end{array}$ & Primer sequence $\left(5^{\prime} \rightarrow 3^{\prime}\right)$ & $\operatorname{Tm}\left({ }^{\circ} \mathbf{C}\right)$ & $\begin{array}{l}\text { Product } \\
\text { length }\end{array}$ & Metabolic function \\
\hline BT-5' & GCACCCTCAAGCTCTCCA & 64.8 & $105 \mathrm{bp}$ & $\beta$ - tubulin - reference gene \\
\hline Bt-3' & AGTTGAGCTGACCAGGGAAA & 64.2 & & \\
\hline Thi-J-5', & AAGCGGGCTACGTCAAATAA & 63.7 & $220 \mathrm{bp}$ & Small peptide protease \\
\hline Thi-J-3' & CAGTCGCCCTCAGTTCTACC & 64.2 & & \\
\hline QUTD1-5' & GCTGAGATTGCACCTCCTTC & 64.3 & $149 \mathrm{bp}$ & Quinate transporter \\
\hline QUTD1-3' & GGCTACAGGAATGTGCCACT & 64.4 & & \\
\hline EPSP-5 & ACATCCACAAGTGGTCGTGA & 64.7 & $167 \mathrm{bp}$ & 5-enolpyruvylshikimate-3- \\
\hline EPSP-3' & AAACGGACGACAAATTCGAG & 64.2 & & phosphate synthase \\
\hline QUTA-5' & TCATCTCCAGATCGTGACCA & 64.9 & $181 \mathrm{bp}$ & Activator of QUT pathway \\
\hline QUTA-3' & GAGATTGCCGCTTTCTTTTG & 64.0 & & \\
\hline FDH-5 & CCCGTCTGTTGGGTACAACT & 64.1 & $166 \mathrm{bp}$ & Formate dehydrogenase \\
\hline FDH-3' & TATCCTGGGTGGAATGGTGT & 64.4 & & \\
\hline AROM-5' & TTCTCCACACGAAGTCTGC & 62.2 & $182 \mathrm{bp}$ & Pentafunctional AROM gene \\
\hline AROM-3' & CCTCGGACGACAAAGCTCT & 64.9 & & \\
\hline $\mathrm{C} 45-5$ & CCACTGTCCACTGTTCGAGA & 64.6 & $198 \mathrm{bp}$ & Trans-membrane \\
\hline C45-3' & GTGGGCAGCCTACAGGAATA & 63.6 & & protein \\
\hline $\mathrm{C} 36-5$ & CGAAATGCAAGATAGCGTCA & 64.2 & $182 \mathrm{bp}$ & General transporter \\
\hline C36-3' & CCACCGAGTTGAAGATGGTT & 64.3 & & \\
\hline C12-5 & ACCACAAGCTCGAAGTCTGC & 64.9 & $157 \mathrm{bp}$ & Cell wall biogenesis \\
\hline C12-3' & TTCGAGTGCTTCTTGCATTG & 64.5 & & \\
\hline PRO41-5 & TCGCAAATTCTTCTGGGACT & 64.0 & $170 \mathrm{bp}$ & Fungal pathogenesis \\
\hline PRO41-3' & CGAGAACAAGGGACATGACA & 64.2 & & \\
\hline SEC72-5' & TCCACCACAAGTTACGGACA & 64.5 & $173 b p$ & Fungal pathogenesis \\
\hline SEC72-3' & CCTCTCGGGCTAGTGTATGC & 64.0 & & \\
\hline
\end{tabular}

*Primer name abbreviations are as follows: $\beta$ - tubulin (BT), 5-enolpyruvylshikimate-3-phosphate synthase (EPSP), formate dehydrogenase (FDH), contig 45 (C45), and contig 36 (C36).

\section{RESULTS}

\section{EST Library and Gene Ontology}

The Rhs1AP subtracted EST library yielded a total 514 high quality tags from the initial 713 subtracted cDNAs. The ESTs ranged from 77 to $820 \mathrm{bp}$ and gave sufficient information for subsequent identification of putative gene functions and are submitted to GenBank (dbEST) with accession numbers between GE139784 to GE140311. Analysis of the transcripts used by $R$. solani in the context of these circumstances revealed a striking pattern in the fact that the majority of the genes that were expressed in response to QA treatment were classified into the broad categories of 'protein 
modification' (GO:0006464) and 'stress response' (GO:0006950) (Table 2). Other genes observed were associated with gluconeogenesis, amino acid metabolism, signaling, lignin degradation and peptidoglycan binding. The category 'stress response' is expected as there is plant-fungus interaction at the time of SSH library preparation. The category 'protein modification' has been the most biologically interesting one and is further explored in this study.

Table 2 Transcript abundance in QA-induced SSH EST library and their putative metabolic roles.

\begin{tabular}{|c|c|c|c|c|c|}
\hline $\begin{array}{l}\text { Unige } \\
\text { ne id. }{ }^{1}\end{array}$ & $\begin{array}{l}\text { Number } \\
\text { of Reads }\end{array}$ & Gene homologue & GenBank Accession & Metabolic Role & E-value \\
\hline $\mathrm{C} 1$ & 60 & Thi-J/PfpI & XM_002794515 & Protein modification & $3.00 \mathrm{E}^{-20}$ \\
\hline $\mathrm{C} 45$ & 36 & RTA1 like protein & XP_002470008 & $\begin{array}{l}\text { Trans-membrane, } \\
\text { detoxification }\end{array}$ & 1.10 \\
\hline C 12 & 34 & Hypothetical protein & $X P \_566997$ & Cell wall organization & $2.00 \mathrm{E}^{-24}$ \\
\hline C 10 & 31 & Beta-glucuronidase & XP_001400317 & $\begin{array}{l}\text { Fungal proliferation and } \\
\text { development }\end{array}$ & $3.00 \mathrm{E}^{-24}$ \\
\hline C 7 & 26 & Urate oxidase & XP_001882203 & Purine metabolism & $1.00 \mathrm{E}^{-08}$ \\
\hline C 24 & 26 & Catalase & $X P \_001889495.1$ & Detox peroxide & $4.00 \mathrm{E}^{-32}$ \\
\hline C 27 & 17 & LysM & XP_001830702 & $\begin{array}{l}\text { Peptidoglycan binding } \\
\text { function }\end{array}$ & 0.089 \\
\hline C 57 & 17 & SBDS & XP_001873294 & $\begin{array}{l}\text { Translational activation of } \\
\text { ribosome }\end{array}$ & 0.001 \\
\hline C 5 & 12 & $\begin{array}{l}\text { FrAG } \\
\text { family }\end{array}$ & $X P \_001243384.1$ & Lysosomal protein & 0.002 \\
\hline C 6 & 12 & $\begin{array}{lr}\text { Gamma } & \text { interferon } \\
\text { inducible } & \text { lysosomal } \\
\text { thiol reductase } & \text { (GILT) }\end{array}$ & XP_762512 & Protein metabolism & $1.00 \mathrm{E}^{-11}$ \\
\hline C 11 & 12 & $\begin{array}{l}\text { Peroxin-13_N and SH3 } \\
\text { domains }\end{array}$ & XP_569688 & $\begin{array}{l}\text { Role in the regulation of } \\
\text { enzymes }\end{array}$ & $7.00 \mathrm{E}^{-101}$ \\
\hline C 4 & 11 & NDP kinases & XM_001833947 & $\begin{array}{l}\text { Regulation } \\
\text { development }\end{array}$ & $4.00 \mathrm{E}^{-04}$ \\
\hline $\mathrm{C} 2$ & 10 & NA & $N A$ & NA & NA \\
\hline $\mathrm{C} 48$ & 10 & 28S ribosomal RNA & EF661648 & Structural RNA & $6.00 \mathrm{E}^{-36}$ \\
\hline $\mathrm{C} 23$ & 9 & Mannose-specific lectin & XM_001016691 & $\begin{array}{l}\text { Involved in alpha-D- } \\
\text { mannose recognition }\end{array}$ & $5.00 \mathrm{E}^{-11}$ \\
\hline C 26 & 9 & $\begin{array}{l}\text { Proteasome beta type- } 2 \\
\text { subunit }\end{array}$ & $X M \_001841260$ & $\begin{array}{l}\text { Nonlysosomal protein } \\
\text { degradation }\end{array}$ & $6.00 \mathrm{E}^{-24}$ \\
\hline C 34 & 9 & Bromo Adjacent & XP_001833175 & Chromatin restructuring & 0.004 \\
\hline C 3 & 7 & $\begin{array}{l}\text { Homology domain } \\
\text { Glyoxal oxidase }\end{array}$ & XP_001833162 & $\begin{array}{l}\text { Extra cellular lignin } \\
\text { degradation }\end{array}$ & $7.00 \mathrm{E}^{-34}$ \\
\hline C 33 & 7 & $\begin{array}{l}\text { Rho GDP-dissociation } \\
\text { inhibitor }\end{array}$ & $X P \_572016.1$ & Signaling & $1.00 \mathrm{E}-{ }^{38}$ \\
\hline C 14 & 6 & $\begin{array}{l}\text { Serine/threonine protein } \\
\text { kinase }\end{array}$ & DR774710 & Signaling & 0.01 \\
\hline C 41 & 6 & Formate dehydrogenase & AB307683 & Glyoxylate pathway & $7.00 \mathrm{E}-63$ \\
\hline C 21 & 5 & NA & $N A$ & NA & NA \\
\hline C 29 & 5 & Fumarate reductase & $X P \_001880208.1$ & Metabolic pathway & $2.00 \mathrm{E}-05$ \\
\hline C 37 & 5 & Hexose transporter & $X P \_001836437.1$ & Transporter protein & $2.00 \mathrm{E}^{-105}$ \\
\hline C 38 & 5 & NA & $N A$ & NA & NA \\
\hline C 56 & 5 & $\begin{array}{l}\text { Acetyl-coenzyme } \\
\text { synthetase }\end{array}$ & $X P \_001840583.1$ & Metabolic pathway & $7.00 \mathrm{E}^{-101}$ \\
\hline C 8 & 4 & Aspartic peptidase & $X P \_001887928.1$ & $\begin{array}{l}\text { Cellular response to } \\
\text { starvation }\end{array}$ & $6.00 \mathrm{E}^{-28}$ \\
\hline C 9 & 4 & Gpr1 family protein & AAX51849 & Transmembrane signaling & $3.00 \mathrm{E}^{-37}$ \\
\hline C 13 & 4 & $\mathrm{ABC}$ transporter & $X P \_757578.1$ & Transporter protein & $4.00 \mathrm{E}^{-52}$ \\
\hline
\end{tabular}




\begin{tabular}{|c|c|c|c|c|c|}
\hline $\begin{array}{l}\text { Unige } \\
\text { ne id. }{ }^{1}\end{array}$ & $\begin{array}{l}\text { Number } \\
\text { of Reads }\end{array}$ & Gene homologue & GenBank Accession & Metabolic Role & E-value \\
\hline C 18 & 4 & $\begin{array}{l}\text { 16S-like small subunit } \\
\text { rRNA gene }\end{array}$ & U09539 & Basidiomycete symbiont & $2.00 \mathrm{E}^{-107}$ \\
\hline C 19 & 4 & Oxalate decarboxylase & XM_001836586 & Glyoxylate metabolism & $1.00 \mathrm{E}^{-04}$ \\
\hline $\mathrm{C} 28$ & 4 & Hypothetical protein & XM_001836226 & Transmembrane protein & $2.00 \mathrm{E}^{-12}$ \\
\hline C 30 & 4 & Hypothetical protein & $X P \_001831416.1$ & Mitochondrial carrier & $1.00 \mathrm{E}^{-26}$ \\
\hline C 32 & 4 & NA & $N A$ & NA & NA \\
\hline $\mathrm{C} 42$ & 4 & NA & $N A$ & NA & NA \\
\hline C 51 & 4 & NA & AER06801 & NA & $2.00 \mathrm{E}^{-23}$ \\
\hline C 59 & 4 & Hmp1 & $X P \_569409.1$ & Cell Adhesion & $2.00 \mathrm{E}^{-09}$ \\
\hline C 17 & 4 & $\begin{array}{l}\text { Thiamine biosynthesis } \\
\text { protein }(\mathrm{Nmt} 1)\end{array}$ & NW__001884670 & Stress related & $9.00 \mathrm{E}^{-28}$ \\
\hline C 31 & 3 & Cytochrome c oxidase & EU237475.1 & Energy metabolism & $5.00 \mathrm{E}^{-04}$ \\
\hline C 35 & 3 & $40 \mathrm{~S}$ ribosomal protein & $X P \_002475466.1$ & Translation & $9.00 \mathrm{E}^{-63}$ \\
\hline C 39 & 3 & $\begin{array}{l}\text { Peroxisomal membrane } \\
\text { protein }\end{array}$ & XP_001828594.2 & Stress related & $4.00 \mathrm{E}^{-20}$ \\
\hline C 52 & 3 & Hypothetical protein & XM_001886834.1 & NA & $4.00 \mathrm{E}^{-47}$ \\
\hline C 54 & 3 & Acetyl xylan esterase & FJ536255 & Act on carboxylic esters & $6.00 \mathrm{E}^{-60}$ \\
\hline C 15 & 2 & Hmp1 & $X P \_569409.1$ & Cell Adhesion & $3.00 \mathrm{E}^{-15}$ \\
\hline C 16 & 2 & Hypothetical protein & AF020765.1 & NA & $5.00 \mathrm{E}^{-06}$ \\
\hline C 22 & 2 & $\begin{array}{l}\text { Flavin-binding } \\
\text { monooxygenase }\end{array}$ & EDR04070 & $\begin{array}{l}\text { Tyrosine/ Tryptophan } \\
\text { metabolism }\end{array}$ & $3.00 \mathrm{E}^{-21}$ \\
\hline C 25 & 2 & $\begin{array}{l}\text { Translocation protein } \\
\text { SEC62 }\end{array}$ & XP_001935299.1 & ER protein translocation & $3.00 \mathrm{E}^{-25}$ \\
\hline C 36 & 2 & $\begin{array}{l}\text { Carbohydrate binding } \\
\text { protein }\end{array}$ & XP_001830003.1 & $\begin{array}{l}\text { Chitin/cellulose binding } \\
\text { domain }\end{array}$ & $4.00 \mathrm{E}^{-32}$ \\
\hline $\mathrm{C} 40$ & 2 & $\begin{array}{l}\text { NADP-dependent } \\
\text { oxidoreductase }\end{array}$ & XP_002475918 & NA & $3.00 \mathrm{E}^{-32}$ \\
\hline C 43 & 2 & NA & $N A$ & NA & NA \\
\hline C 44 & 2 & Ubiquitin & XP_002551417 & $\begin{array}{l}\text { Post-translational } \\
\text { modification }\end{array}$ & $8.00 \mathrm{E}^{-07}$ \\
\hline C 46 & 2 & ATPase & DR775326 & $\begin{array}{l}\text { Ubiquitin-dependent } \\
\text { protein }\end{array}$ & $4.00 \mathrm{E}^{-68}$ \\
\hline C 47 & 2 & NA & $N A$ & NA & NA \\
\hline C 49 & 2 & Hypothetical protein & XM_002397290.1 & NA & $5.00 \mathrm{E}^{-05}$ \\
\hline C 50 & 2 & RNA recognition motif & $X P \_001876504$ & Signaling & $9.00 \mathrm{E}^{-04}$ \\
\hline C 53 & 2 & Endopeptidase & XP_001874304.1 & $\begin{array}{l}\text { Cellular response to } \\
\text { starvation }\end{array}$ & $2.00 \mathrm{E}^{-52}$ \\
\hline C 55 & 2 & NA & $N A$ & NA & NA \\
\hline C 58 & 2 & ABC Trasporter & AB091269 & NA & $4.00 \mathrm{E}^{-13}$ \\
\hline S 3 & 1 & Sugar transporter & $X P \_001216538.1$ & NA & 0.01 \\
\hline S 56 & 1 & Peptidase inhibitor I9 & XM_001543539 & Molecular chaperones & $7.00 \mathrm{E}^{-06}$ \\
\hline S 526 & 1 & $\begin{array}{ll}\text { Major } & \text { Facilitator } \\
\text { Superfamily } & \end{array}$ & XP_002472048.1 & Transporter protein & $3.00 \mathrm{E}^{-11}$ \\
\hline S 541 & 1 & Protease & $A D D 71498$ & Protein modification & $6 e-34$ \\
\hline S567 & 1 & $\begin{array}{l}\text { 40S ribosomal protein } \\
\text { S18 }\end{array}$ & EAU91281 & Translation & $7.00 \mathrm{E}^{-04}$ \\
\hline S 585 & 1 & $\begin{array}{l}\text { RNA polymerase II } \\
\text { transcription factor }\end{array}$ & $X P \_572300.1$ & NA & $3.00 \mathrm{E}^{-71}$ \\
\hline S 607 & 1 & Glucosidase & AY371490 & Anti-bacterial & $3.00 \mathrm{E}^{-08}$ \\
\hline S 616 & 1 & Isocitrate lyase & EER43895.1 & Glyoxylate pathway & $2.00 \mathrm{E}^{-12}$ \\
\hline S 639 & 1 & $\begin{array}{l}\text { Scavenger mRNA } \\
\text { decapping enzyme }\end{array}$ & XP_002470400.1 & $\mathrm{NA}$ & 0.05 \\
\hline S 661 & 1 & RNA-binding protein & ВХ649605.1 & $\begin{array}{l}\text { Translation, ribosomal } \\
\text { structure and biogenesis }\end{array}$ & $5.00 \mathrm{E}^{-06}$ \\
\hline S 670 & 1 & Riboflavin synthase & CAX41869 & Vitamin Metabolism & $7.00 \mathrm{E}^{-04}$ \\
\hline S 679 & 1 & Thi-J/PfpI & $X P \_002152465.1$ & Protease & $3.00 \mathrm{E}^{-15}$ \\
\hline
\end{tabular}




\begin{tabular}{|c|c|c|c|c|c|}
\hline $\begin{array}{l}\text { Unige } \\
\text { ne id. }{ }^{1}\end{array}$ & $\begin{array}{l}\text { Number } \\
\text { of Reads }\end{array}$ & Gene homologue & GenBank Accession & Metabolic Role & E-value \\
\hline S 687 & 1 & MFS & $X P \_002472048.1$ & Transporter protein & $3.00 \mathrm{E}^{-06}$ \\
\hline S 705 & 1 & $\begin{array}{l}\text { Formaldehyde } \\
\text { dehydrogenase }\end{array}$ & $X P \_568318.1$ & Stress related & $3.00 \mathrm{E}^{-04}$ \\
\hline S 261 & 1 & $\begin{array}{l}\text { Eukaryotic translation } \\
\text { initiation factor }\end{array}$ & $X P \_002469815.1$ & Translation & $7.00 \mathrm{E}^{-31}$ \\
\hline S 298 & 1 & $\begin{array}{l}\text { Xanthine } \\
\text { phosphoribosyl } \\
\text { transferase }\end{array}$ & $X P \_960504.1$ & $\begin{array}{l}\text { Purine nucleotide } \\
\text { biosynthesis }\end{array}$ & $8.00 \mathrm{E}^{-24}$ \\
\hline S 369 & 1 & Alpha amylase & XP_001838963.1 & NA & $4.00 \mathrm{E}^{-38}$ \\
\hline S 380 & 1 & $\mathrm{NA}$ & $N A$ & NA & NA \\
\hline S 399 & 1 & $\begin{array}{l}\text { Oligopeptide } \\
\text { transporter }\end{array}$ & XP_002380822.1 & $\begin{array}{l}\text { Aromatic compound } \\
\text { metabolism }\end{array}$ & $6.00 \mathrm{E}^{-05}$ \\
\hline S 422 & 1 & Transposase & YP_002382784.1 & NA & $3.00 \mathrm{E}^{-42}$ \\
\hline S 423 & 1 & C6 transcription factor & $X P \_001837312.1$ & Regulation & $2.00 \mathrm{E}^{-0 \varsigma}$ \\
\hline S 425 & 1 & Dehydrogenase & $X P \_001828376.2$ & NA & $2.00 \mathrm{E}^{-17}$ \\
\hline S 128 & 1 & NA & $N A$ & NA & NA \\
\hline S 137 & 1 & $\mathrm{ABC}$ transporter & $Y P \_002561916.1$ & Transporter protein & 0.10 \\
\hline S 145 & 1 & $\begin{array}{l}\text { Protein zinc finger } \\
\text { domain }\end{array}$ & 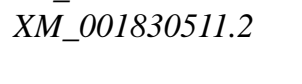 & Regulation & $6.00 \mathrm{E}^{-0 s}$ \\
\hline S 163 & 1 & GTP-binding protein & NC_012491.1 & Metabolism & 0.14 \\
\hline S 166 & 1 & Predicted protein & XP_001834221.1 & NA & $2.00 \mathrm{E}^{-13}$ \\
\hline S 167 & 1 & NA & $N A$ & NA & NA \\
\hline S 469 & 1 & NA & $N A$ & NA & NA \\
\hline
\end{tabular}

${ }^{1}$ Under 'unigene id' column, 'C' and 'S' denotes contig and singleton, respectively.

Forty percent of the QA induced ESTs received GO assignments, the majority (72.7\%) of which were identified as orthologous of fungal genes, with the highest number of hits $(8.5 \%)$ obtained with a single species being from Coprinopsis cinerea (Fig. 1).

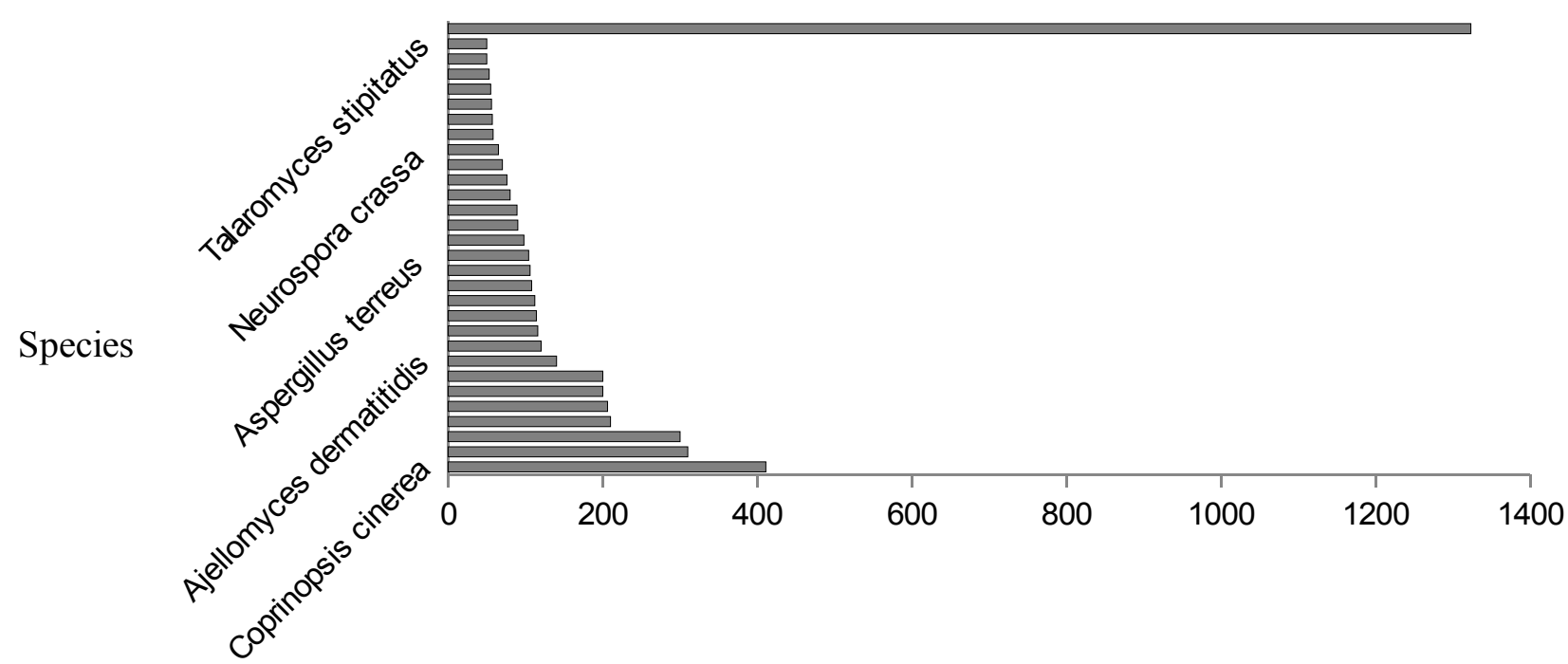

Blast hits

Fig. 1 - Overall BLASTx hits for sequences in the Rhs1AP (AG3) quinic acid-induced ESTs by species based on cut-off significance of $\mathrm{E} \leq 10^{-3}$. 
The majority of 'biological processes' associated with QA induced gene expression were metabolic processes (GO:0008152) and cellular processes (GO:0009987) (Fig. 2). The most prominent GO sub categories under 'cellular processes' were responses to stimuli (GO:0050896), and peroxidase reaction (GO:0004601). The most significantly enriched GO sub categories under 'metabolic process' were carbon utilization (GO:0015976), catabolic process (GO:0009056), catabolic macromolecule metabolic process (GO:0043170) and biosynthetic process (GO:0009058). Other biological process categories such as organization and biogenesis (GO:0030030), cell communication (GO:0007154), regulation of biological process (GO:0050789) and multicellular organismal process (GO:0032501) were also significantly represented suggesting at least a partial overlap with the phenomena of switching carbon source utilization, stress response and gluconeogenesis. This is expected from a fungus responding to newly available carbon source with processing and recycling of intermediates from post translational mechanisms from adaptive stress.

\section{Biological processes}
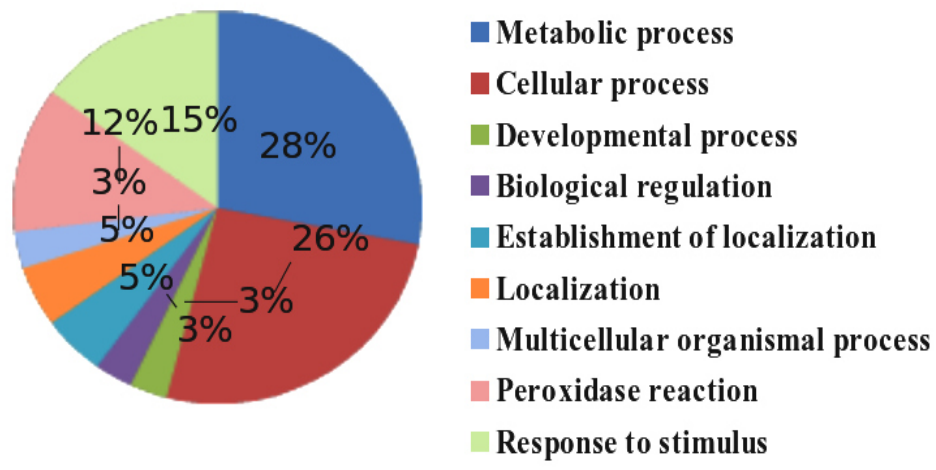

Cellular Component

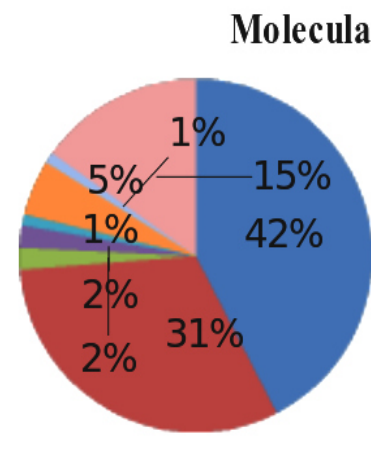

function

Catalytic activity

Binding

Transcription regulation activity

- Structural molecule activity

- Translational regulator activity

Transporter activity

Nutrient reservoir activity

Antioxidant activty

Fig. 2 - Results from Gene Ontology analysis visualizing the hierarchical structure of suppression subtractive hybridization EST library. 
About $75 \%$ of the ESTs were successfully assigned to their specific cellular (organelle) locations based on the results of the GO annotation (Fig. 2). The macromolecular complex (11\%) included the protein complex and the ribo-nucleoprotein complex. 'Molecular function categories' explain the function of a gene at the biochemical level. In this category, most ESTs belonged to the catalytic activity, binding, and peroxidase groups. Of the total processes under the molecular function level, $74 \%$ belonged to the catalytic and binding categories. The catalytic category include ligases, lyases, helicases, small protein activating enzymes and transposases. Majority of the EST's falling to cataltyic activity groups could indicate an increased restructuring happening at cellular level in the fungus. These results are also in congruence with the phenomena of stress response, a shift in carbon utilization and active protein modification by the fungus.

Of the 514 clones sequenced, 226 returned with significant matches $\left(E \leq 10-{ }^{3}\right)$ when searched against the KEGG non redundant database for pathway analysis, whereas 297 sequences showed no similarity at this level (Table 3 ). Of the 226 tags that showed metabolic pathway information, protein folding and degradation (93/226 members), amino acid metabolism (33/226 members), membrane transport (32/226 members), nucleotide metabolism (25/226 members), carbohydrate metabolism (20/226) and signaling (10/226 members) were the most highly represented process categories. Results of GO revealed that $15 \%$ of ESTs that belong to the 'biological process category' were involved in 'responses to stimuli' (GO:0050896), whereas KAAS classified the same group under the 'signaling pathway' process category, which is considered as an offspring category of the 'responses to stimuli' group (data not shown). Pathogenic fungus's close proximity with two different substrates (Potato and QA) leads to fungal cellular responses to chemical cues from substrates and the 'responses to stimuli' category being enriched in the EST is an indication of this event. These trends are consistent with the earlier findings that treatment with QA leads to the activation of the stress response pathway and significant changes in the mode of carbon utilization by the fungus (Table 2).

Table 3 KEGG biochemical pathway mapping for QA-induced unigenes in Rhs 1AP R. solani (AG3).

\begin{tabular}{ll}
\hline KEGG category & Genes represented \\
\hline 01100 Metabolism & 20 \\
01101 Carbohydrate Metabolism & 8 \\
01102 Energy Metabolism & 25 \\
01104 Nucleotide Metabolism & 33 \\
01105 Amino Acid Metabolism & 1 \\
01109 Metabolism of Cofactors and Vitamins & 2 \\
01111 Xenobiotics Biodegradation and Metabolism & \\
01120 Genetic Information Processing & 1 \\
01121 Transcription & 10 \\
01122 Translation & 93 \\
01123 Folding, Sorting and Degradation & 1 \\
01124 Replication and Repair & 32 \\
01130 Environmental Information Processing & 297 \\
01131 Membrane Transport & \\
Unknown function &
\end{tabular}

\section{Expression profiling of candidate genes from the EST library}

Two genes encoding ABC transporters (QUTD (GenBank accession FJ348680.1) and C36) showed high levels of transcription shortly after treatment with QA. As expected, the transcription activator QUTA (GenBank accession FJ348679.1) exhibited a low and consistent level of expression throughout the entire period of the experiment (Fig. 3).The gene QUTA encodes an activator protein for the QA pathway and is known to have constitutive expression when QA pathway is induced (Lakshman et al. 2006). 
Interestingly, a gene encoding a putative small peptide protease (FJ348681.1) (Thi J), which is the most highly represented transcript in the AG3 library, showed a high level of transcription $30 \mathrm{~min}$ after QA treatment suggestive of extensive protein modifications following application of QA. This gene exhibited further increases in transcript abundance 3 hours after QA treatment before leveling off to nearly basal level by 8 hours after QA treatment (Fig. 4). Gene C12 encoding a putative SSD1 like protein showed a significant change in the level of expression at 36 hours post induction (PI) (Fig. 4) whereas the putative gene C45, encoding an RTA1 like protein, showed a sharp increase in its expression 18 hours after QA induction (Fig. 4).

The SHK pathway AROM gene had a substantial increase in its relative expression level at 18 hours after the QA treatment (Fig. 5), which is consistent with our earlier report (Lakshman et al. 2006). Another shikimic acid pathway gene, EPSP, was also induced in a similar manner (Fig. 5) whereas a formate dehydrogenase ortholog (C41) was expressed at a relatively high level 30 min PI but its transcription was reduced substantially until 36 hours PI when transcript level again increased again dramatically (Fig. 5). Two genes thought to be involved in fungal pathogenesis ( $F$ box domain protein Sec72 and Pro41) (Rioux et al. 2011) were found to be downregulated (Fig. 6) in the presence of QA and potato host.

Upon hierarchical clustering analysis, the genes selected for the expression study were separated into 3 clusters (Fig. 5). C45, EPSP, AROM, and QUTA formed the first cluster, with significant upregulation at $18 \mathrm{hrs}$ after exposure to QA. The second cluster consisted of ThiJ, QUTD, and C36. Genes in the second cluster were upregulated early after QA treatment and exhibited decreasing expression after this initial phase, though the exact timing and pattern of this decrease varied within the cluster. FDH and $C 12$ were grouped in the third cluster due to their high expression levels during the later stages following QA treatment ( $36 \mathrm{hr}$ ) though $F D H$ also exhibited an initial peak of expression ( $0.5 \mathrm{hr}$ after QA treatment).

Genes clustered in the hierarchical clustering analysis for the expression study reveals similar patterns among for all three QA pathway related genes (EPSP, AROM, and QUTA) as well as an RTA1 like protien, a trans-membrane protein involved in detoxification. The second cluster involved two transporter genes (QUTD, and C36) and a small peptidase gene, Thi-J. At this level of research, the role of Thi-J is speculative only. But, this small peptidase gene has significant expression change during QA induction. The third group comprised SSD1 like gene (C21) and glyoxylate pathway gene $(\mathrm{FDH})$ and such grouping shed little light to explain the molecular mechanisms in this study.

\section{Discussion}

This study provided evidence on the important role of QA in rhizosphere dynamics and its regulatory role in pathogenesis/ saprophytism for $R$. solani AG3 in Potato. QA is abundant in the soil, comprising 2 to $10 \%$ of the dry weight of compost (Leuschner et al. 1995). Compost is often incorporated in to cultural practices in growing potato (Larkin et al. 2007a, Larkin et al. 2011). Under such conditions, QA could be the sole carbon source for soil bacteria and fungi (Hawkins et al.1993). These results provide an initial account of the molecular basis of QA induced hypovirulence in $R$. solani and are in congruence with field data showing a potential for exploitation of this phenomenon for management of major crop diseases incited by this organism (Bandy \& Tavantzis 1990, Larkin et al. 2007b). Although the results of the subtractive hybridization were validated through qRT PCR gene expression profiling, no function determination studies were performed in this study. This is due to the lack of suitable mutants or a transformation system with which to test gene knockouts or other useful tools for determining gene function in $R$. solani. The putative gene functions discussed here, however, will serve as a guide in future studies with systems for functional analysis protocols are available for $R$. solani. This study showed an enrichment of QUT pathway associated genes, and a total of 94 unigenes differentially expressed in response to QA induction (Table 2). Most changes were indicative of carbon metabolism, protein degradation and modification, amino acid metabolism and ribosome biosynthesis and assembly. 
A)

QUTD1

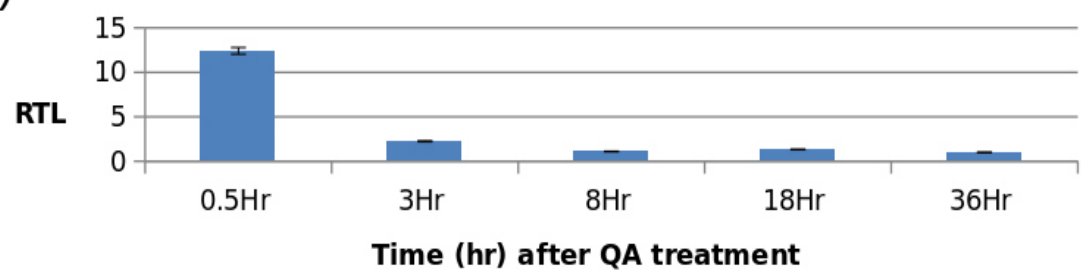

B)

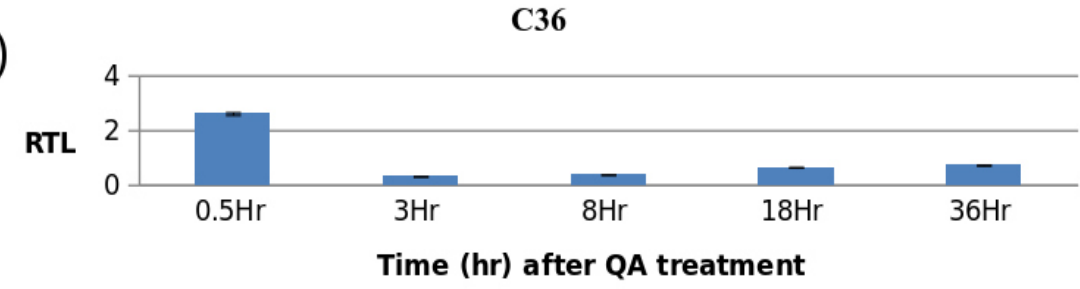

C)

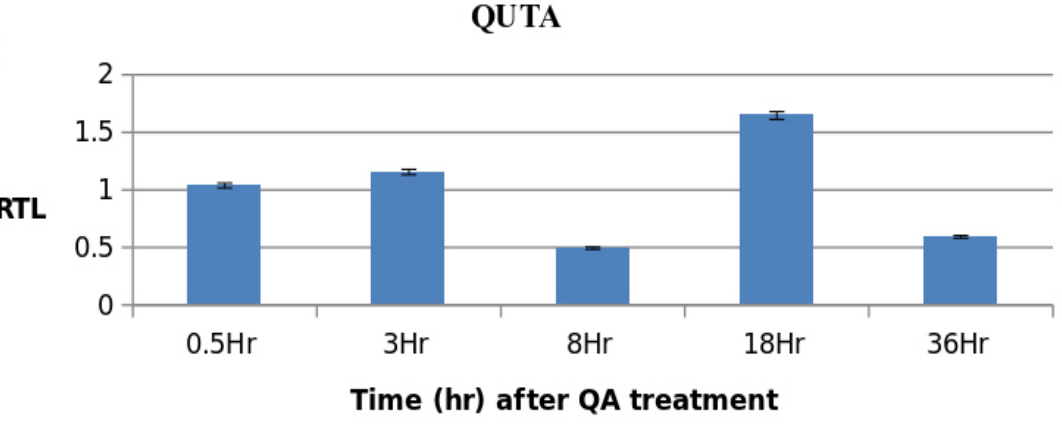

Fig. 3 - Time course expression profiles of putative quinate utilization (QUT) pathway SSH subtracted genes in Rhs 1AP $R$. solani (AG3) after treatment with QA in the presence of sprouting potato tubers. A) putative quinic acid transporter QUTD1, B) C36, C) putative QUTA).

\section{Quinic acid application leads to stress adaptation and resource recycling}

QA induced SSH library of $R$. solani predominantly were populated by genes involved in protein modification like Thi J/PfpI like family (Wei 2007), proteasome $\beta$ type 2 subunit (Phan et al. 2000), and an endopeptidase like protein (Johnson 2004). The presence of these genes in the QA induced SSH library appears to indicate a shift in biosynthesis from basic building blocks or other intermediates to peptide and amino acid recycling after QA treatment. Furthermore, expression of several components of the ubiquitin pathway (ubiquitin and ATPase involved in ubiquitin mediated proteolysis) under QA induction is indicative of the post translational mechanisms that may be required for the processing of newly synthesized polypeptides from recycled substrates or intermediates. Genes involved in metabolism of purine bases, including a putative urate oxidase and xanthine phosphoribosyl transferase, were found to be well represented in the QA induced SSH library (Table 2 ), suggesting important roles in mechanisms for recycling resources under stress conditions. The presence of $\mathrm{G}$ protein coupled receptor (Gprl) is consistent with the assumption that QA triggers a shift in nitrogen metabolism.Gprl is a nutrient sensor protein which is reported to be induced by nitrogen starvation and to play an important role in the regulation of dimorphic transition in the budding yeast Saccharomyces cerevisiae (Lorenz et al. 2000). Future studies dealing with the effects of various nitrogen sources on growth and gene expression of $R$. solani in the presence or absence of QA should provide detailed information on the effect of QA on nitrogen metabolism in this fungus. 
A)

Thi-J

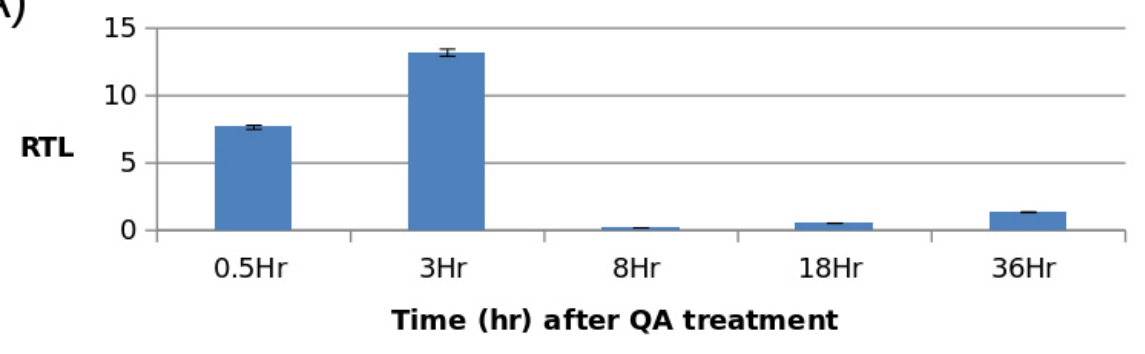

B)

$\mathrm{C12}$
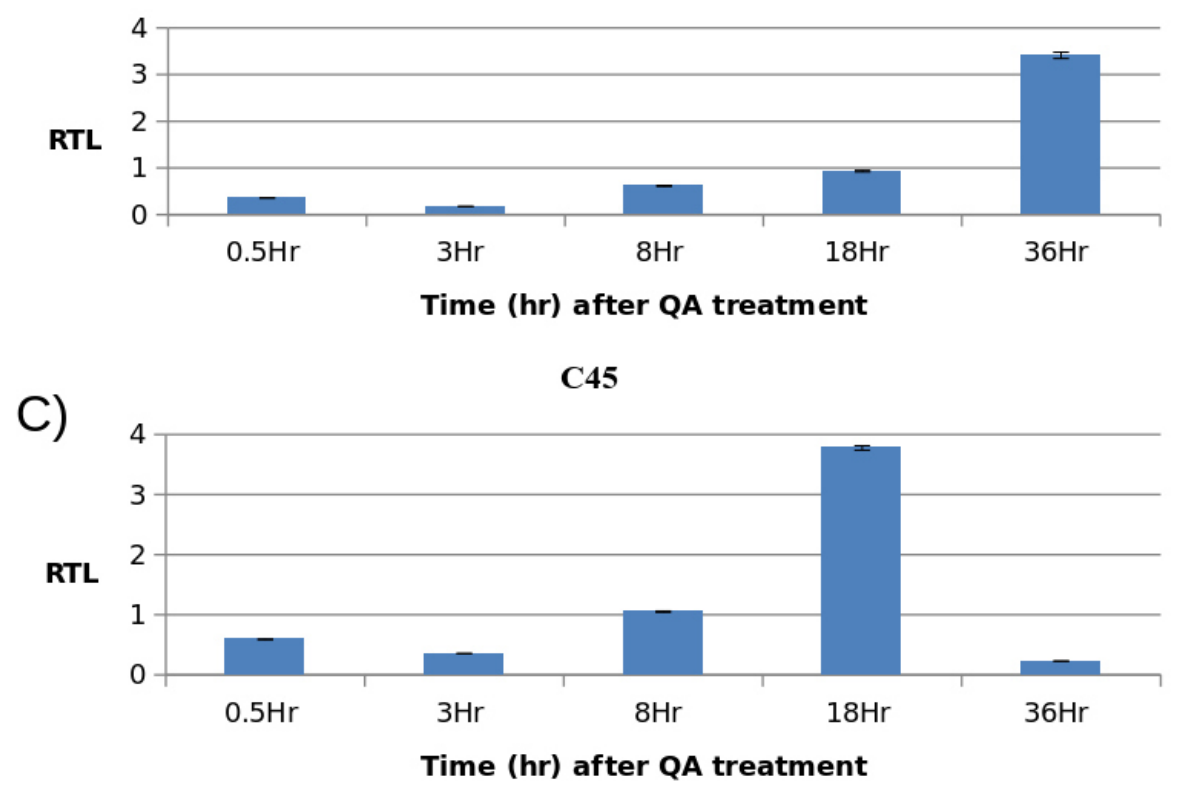

Fig. 4 - Time course expression profiles of some predominant SSH subtracted ESTs in Rhs 1AP $R$. solani (AG3) after treatment with QA in the presence of sprouting potato tubers. A) C1 (Thi J like protein small peptide protease), B) C12 (SSD1 like protein), C) C45 (RTA1 like protein).

\section{Analysis of QA induced gene expression}

The two QUT pathway genes, QUTA and QUTD that we examined showed similar QA induced temporal induction profiles as their orthologous genes in $N$. crassa under QA induction (Logan et al. 2007). As expected, the transcription activator QUTA was expressed at relatively low levels throughout the course of the experiment peaking at 18 hours after application of exogenous QA (Fig. 1). The QUT pathway QA transporter gene QUTD exhibited a rapid and transient induction profile characterized by a rapid peak as early as $30 \mathrm{~min}$ after exposure to exogenous QA before leveling off to nearly basal levels at $3 \mathrm{hrs}$ after QA treatment. The other transporter gene represented by contig C36 had the same expression pattern as QUTD (1A \& 1B). The Thi $j$ gene was induced to a high level within the first 3 hours after exposure to exogenous QA (Fig. 1). This pattern is consistent with the putative function of this gene in protein degradation and further implies a state of high metabolic activity and protein turnover and recycling soon after exposure to exogenous QA. A gene encoding a putative trans membrane detoxification protein, RTA 1 like protein (contig C45), was transiently induced within the first 18 hours after exposure to exogenous QA (Fig. 1). In contrast, the gene for SSD1 like protein (contig C12) was upregulated at a much slower pace with its peak expression occurring not earlier than 

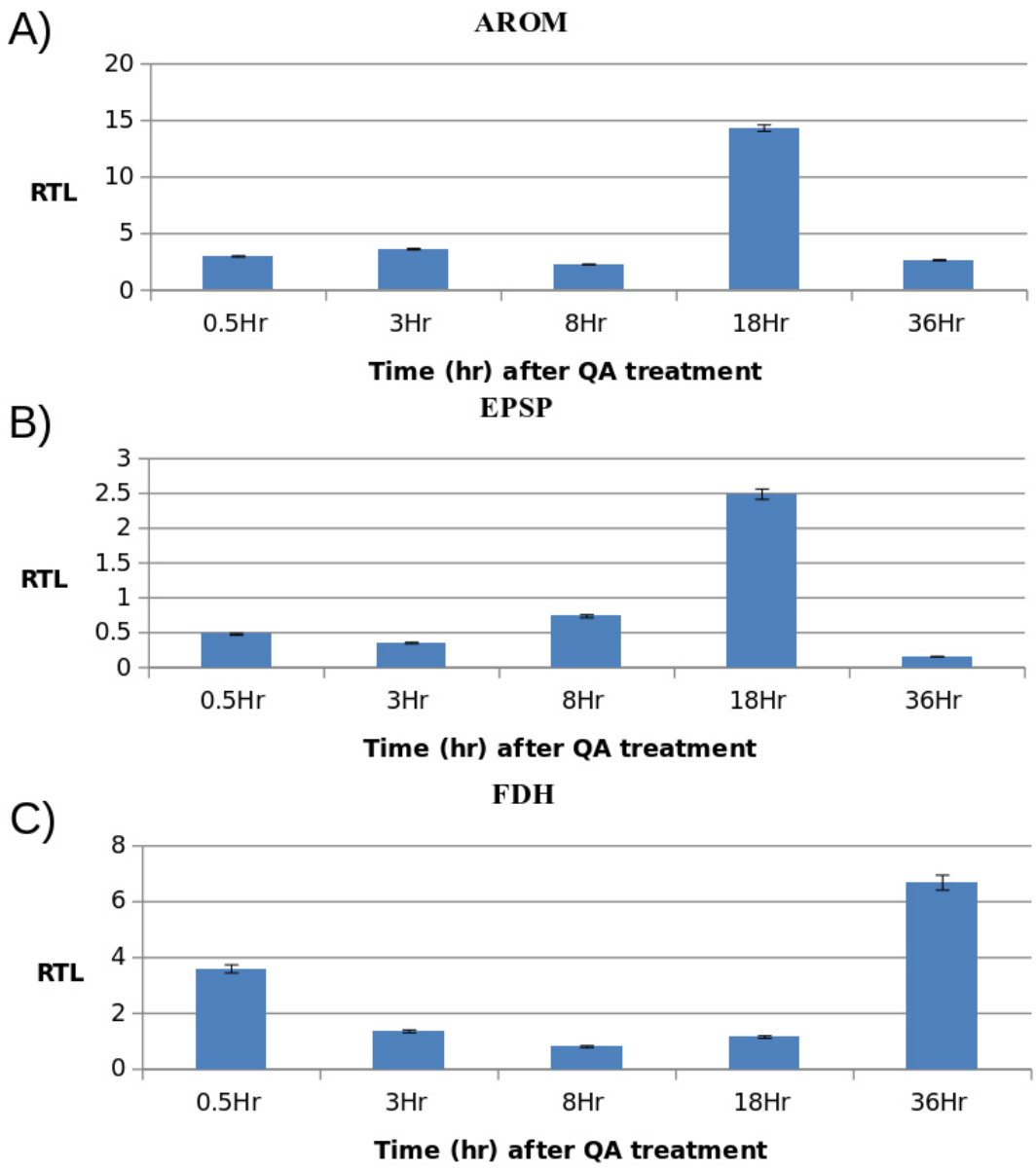

Fig. 5 - Time course expression profiles of two SSH subtracted shikimic acid pathway genes (AROM and EPSP) and a glyoxylate pathway gene (FDH) gene in Rhs 1AP $R$. solani (AG3) after treatment with QA in the presence of sprouting potato tubers. A) AROM, B) putative EPSP, C) C41 (formate dehydrogenase, FDH).

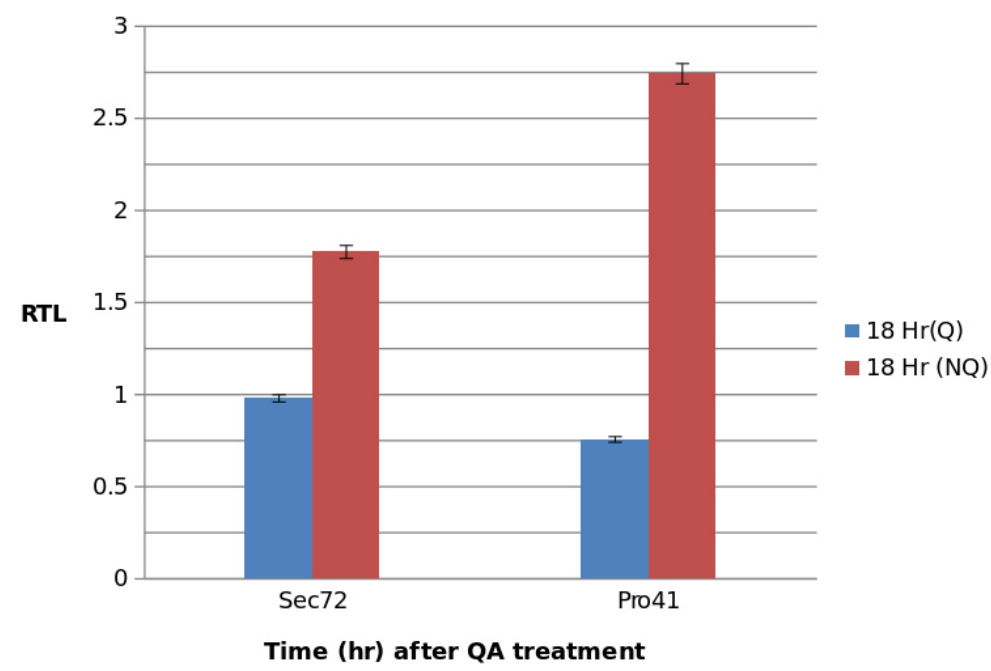

Fig. 6 - Comparison of QA-induced and uninduced relative expression levels of two pathogenesisrelated Rhs 1AP $R$. solani (AG3) genes (sec72 and pro41) 18 hours post-induction with QA 


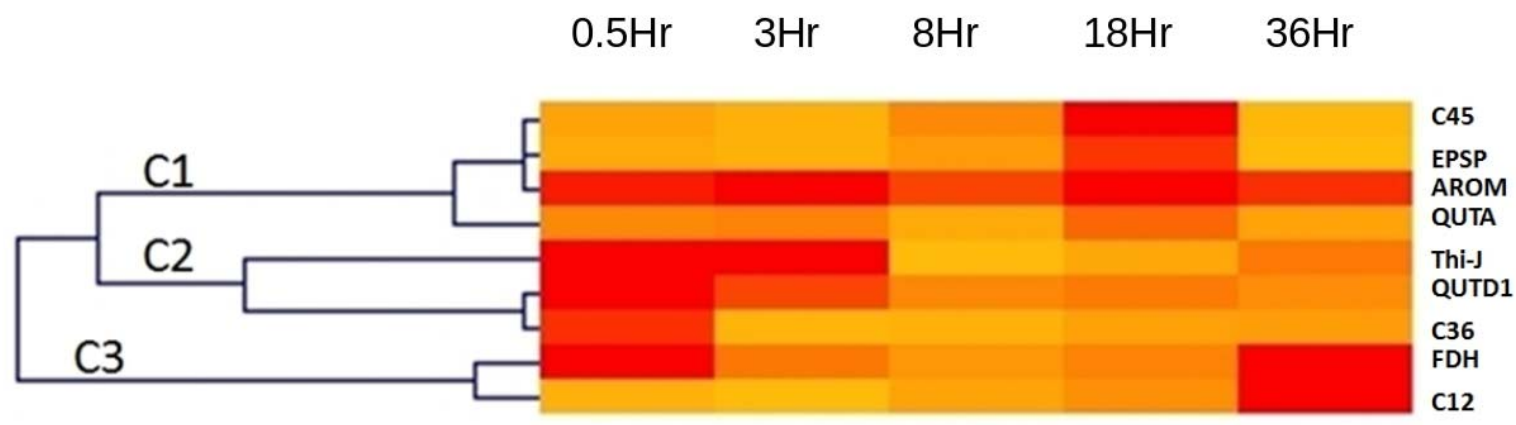

Relative transcriptional level

0.0

3.4106214

Fig. 7 - Hierarchical clustering analysis of time-course expression of selected genes in Rhs 1AP $R$. solani (AG3) following treatment with QA in the presence of sprouting potato tubers.

36 hours after exposure to exogenous QA (Fig. 1). The SSD1 protein is involved in the regulation of cell wall biogenesis by a post transcriptional regulatory mechanism (Ibeas et al. 2001). The product of SSD1 interacts with the components of the TOR pathway, which regulates gene expression associated with nutrient sensing through histone acetylation (Rohde \& Cardenas 2003). An SSD1 mutant of S. cerevisiae exhibited increased virulence (Wheeler et al. 2003). These putative properties make C12 an excellent candidate gene to study in detail to enhance our understanding of virulence as well as QA induced hypovirulence in $R$. solani. The fungal pathogenesis related genes ( $F$ box domain protein Sec72 and Pro 41), upregulated in the AG1 IA/rice and AG3/potato pathosystems (Venu et al. 2007, Rioux et al. 2011), were found to be downregulated by QA treatment in AG3 Rhs1AP (Fig. 2). This result is in congruence with the concept of QA induced hypovirulence in AG3 Rhs1AP.

\section{Potential mechanism of QA induced hypovirulence in $R$. solani AG3}

QA can be utilized as a carbon source by fungi through the $\beta$-ketoadipate pathway where QA is catabolized into protocatechuate. One of the byproducts of the $\beta$-ketoadipate pathway is acetyl CoA which can be further shunted into the citric acid cycle, a metabolic pathway involved in generation of usable energy. The presence of isocitrate lyase, fumarate reductase and acetyl coenzyme A synthetase were represented in the QA induced SSH library suggest the possibility that glyoxylate pathway genes are differentially expressed under QA induction. The glyoxylate pathway is an anabolic metabolic pathway which can be used for synthesis of carbohydrates. The over expression of formate dehydrogenase under QA induction validates this assumption. Another interesting fact is the presence of oxalate decarboxylase in the induced hypovirulence EST library. This enzyme, along with formate dehydrogenase, is involved in the degradation of oxalic acid (OA), a known virulence factor in some fungi (Munir 2001). These patterns suggest that OA may be utilized by the fungus as a source of energy, and that reduced OA levels might be partially responsible for the reduced virulence of QA treated Rhs 1AP. The current findings shed light into understanding the molecular mechanisms in context of pathogenesis, saprophytism and mutualism for $R$. solani.

\section{Acknowledgements}

This work was funded by Maine Agriculture and forest Experiment Station, Maine USA. I thank Dr. Benildo de los Reyes, University of Maine for guidance in gene expression studies. 


\section{References}

Altschul SF, Madden TL, Schaffer AA, Zhang J, Zhang Z, Miller W, Lipman DJ. 1997 - Gapped BLAST and PSI BLAST: A new generation of protein database search programs. Nucleic Acids Research 25, 3389-3402.

Bandy BP, Leach SS, Tavantzis SM. 1988 - Anastomosis group 3 of Rhizoctonia solani is the major cause of Rhizoctonia disease in Maine. Plant Diseases 72, 596-598.

Bandy BP, Tavantzis SM. 1990 - Effect of hypovirulent Rhizoctonia solani on Rhizoctonia disease, growth, and development of potato. American Potato Journal 67, 189-199.

Bernard E, Larkin RP, Tavantzis S, Erich MS, Alyokhin A, Gross SD. 2014 - Rapeseed rotation, compost and biocontrol amendments reduce soilborne diseases and increase tuber yield in organic and conventional potato production systems. Plant and Soil 374, 611-627.

Carling DE. 1996 - Grouping in Rhizoctonia solani by hyphal anastomosis interactions. In: Sneh B, Jabaji Hare S, Neate S, Dijst G, eds. Rhizoctonia Species: Taxonomy, Molecular Biology, Ecology, Pathology and Disease Control. Dordrecht: Kluwer Academic Publishers. p. 37-47.

Conesa A, Götz S, Garcia JM, Terol J, Talon M, Robles M. 2005 - Blast2GO: A universal tool for annotation, visualization and analysis in functional genomics research. Bioinformatics 21, 3674-3676.

Davis RH, deSerres FJ. 1970 - Genetic and Microbiological Research Techniques for Neurospora crassa. Methods in Enzymology 17, 79-143.

Garland JL, Mills AL. 1991 - Classification and characterization of heterotrophic microbial communities on the basis of patterns of community level sole carbon source utilization. Applied and Environmental Microbiology 57, 2351-2359.

Hall T. 2004 - BioEdit. Biological sequence alignment editor for Win95/98/NT/2K/XP.

http://www.mbio.ncsu.edu/BioEdit/bioedit.html

Huang X, Madan A. 1999 - CAP3: A DNA sequence assembly program. Genome Research 9, 868877.

Ibeas J, Yun DJ, Damsz B, Narasimhan ML, Uesono Y, Ribas JC. 2001 - Resistance to the plant PR 5

Protein osmotin in the model fungus Saccharomyces cerevisiae is mediated by the regulatory effects of SSD1 on cell wall composition. Plant Journal 25, 271-280.

Johnson ES. 2004 - Protein modification by SUMO. Annual Review of Biochemistry 73:355-382.

Lakshman DK, Liu C, Mishra PK, Tavantzis SM. 2006 - Characterization of the arom gene in Rhizoctonia solani, and transcription patterns under stable and induced hypovirulence conditions. Current Genetics 49, 166-177.

Lamb HK, Roberts CF, Hawkins AR. 1992 - A second gene (qutH) within the Aspergillus nidulans quinic acid gene cluster encodes a protein with a putative zinc cluster motif. Gene 112, 219224.

Larkin RP, Griffin TS. 2007 - Control of soilborne potato diseases using Brassica green manures. Crop

Protection 27, 1067-1077.

Larkin RP, Manmathan H, Tavantzis SM. 2007a - "Effects of Compost and Biocontrol Amendments on Soilborne Diseases of Potato." Northeast Potato Technology Forum Abstracts.

Larkin RP, Manmathan H, Tavantzis SM. 2007b - Effects of Compost and Biocontrol Amendments on Stem Canker, Black Scurf, and Common Scab of Potato, 2006. Plant Disease Management Reports $1,65$.

Larkin RP, Honeycutt CW, Griffin TS, Olanya OM, Halloran JM, He Z. 2011 - Effects of different potato cropping system approaches and water management on soilborne diseases and soil microbial communities. Phytopathology 101,58-67.

Leuschner C, Herrmann KM, Schultz G. 1995 - The metabolism of quinate in pea roots-purification and partial characterization of quinate hydrolase. Plant Physiology 108, 319-325. 
Liu C, Lakshman DK, Tavantzis SM. 2003a - Quinic acid induces hypovirulence, and expression of a hypovirulence associated double stranded RNA in Rhizoctonia solani. Current Genetics 43, 103-111.

Liu C, Lakshman DK, Tavantzis SM. 2003b - Expression of a hypovirulence causing double stranded RNA (dsRNA) is associated with up regulation of quinic acid pathway, and down regulation of shikimic acid pathway in Rhizoctonia solani. Current Genetics 42, 284-291.

Livak KJ, Schmittgen TD. 2001-Analysis of relative gene expression data using real time quantitative PCR and the 2(Delta Delta C(T)) Method. Methods 25, 402-408.

Logan DA, Koch AL, Dong W, Griffith J, Schüttler HB. 2007- Genome wide expression analysis of genetic networks in Neurospora crassa. Bioinformation 1, 390-395.

Lorenz MC, Pan X, Harashima T, Cardenas MC, Xue Y, Hirsch JP, Heitman J. 2000 - The G protein coupled receptor GPR1 is a nutrient sensor that regulates pseudohyphal differentiation in Saccharomyces cerevisiae. Genetics 154, 609-622.

Moriya Y, Itoh M, Okuda S, Yoshizawa AC, Kanehisa M. 2007- KAAS: an automatic genome annotation and pathway reconstruction server. Nucleic Acids Research 35 Web Server, 182185.

Munir E, Yoon JJ, Tokimatsu T, Hattori T, Shimada M. 2001- A physiological role for oxalic acid

biosynthesis in the wood rotting basidiomycete Fomitopsis palustris. Proceedings of the National Academy of Sciences 98, 11126-11130.

Nowrousian M, Frank S, Koers S, Strauch P, Weitneer T, Ringelberg J, Dunlap C, Loros JJ, Kuck U. 2007- The novel ER membrane protein PRO41 is essential for sexual development in the filamentous fungus Sordoria macrospora. Molecular Microbiology 64, 923-937.

Pfaffl MW. 2001-A new mathematical model for relative quantification in real time RT PCR. Nucleic Acids Research 29, 2002-2007.

Phan UT, Arunachalam B, Cresswell P. 2000 - Gamma interferon inducible lysosomal thiol reductase

(GILT):maturation, activity, and mechanism of action. The Journal of Biological Chemistry 275, 25907-25914.

Rioux RA, Manmathan H, Singh P, de los Reyes B, Jia Y, Tavantzis SM. 2011- Comparative analysis of putative pathogenesis related gene expression in two Rhizoctonia solani pathosystems. Current Genetics 57, 391-408.

Rohde JR, Cardenas ME. 2003 - The tor pathway regulates gene expression by linking nutrient sensing to histone acetylation. Molecular and Cellular Biology 23, 629-635.

Saeed AI, Bhagabati NK, Braisted JC, Liang W. 2006 - TM4 microarray software suite. Methods in Enzymology 411, 134-193.

Soanes DM, Alam I, Cornell M, Wong HM, Hedeler C, Paton NW, Rattray M, Hubbard SJ, Oliver SG, Talbot NJ. 2008 - Comparative genome analysis of filamentous fungi reveals gene family expansions associated with fungal pathogenesis. PLoS One 3, e2300.

Solovyev V, Kosarev P, Seledsov I, Vorobyev D. 2006 - Automatic annotation of eukaryotic genes, pseudogenes and promoters. Genome Biology 1, 10.1-10.12

Venu RC, Jia Y, Gowda M, Jia MH, Jantasuriyarat C, Stahlberg E, Li H, Rhineheart A, Singh P, Rutger N, Kudrna D, Wing R, Nelson JC, Wang G L. 2007 - RL SAGE and microarray analysis of the rice transcriptome after Rhizoctonia solani infection. Molecular Genetics and Genomics 278, 421-431.

Wheeler RT, Kupiec M, Magnelli P, Abeijon C, Fink GR. 2003 - A Saccharomyces cerevisiae mutant with increased virulence. Proceedings of the National Academy of Sciences 100, 2766-2770.

Zheng A, Lin R, Zhang D, Qin P, Xu L, Ai P, Ding L, Wang Y, Chen Y, Liu Y, Sun Z, Feng H, Liang X, Fu R, Tang C, Li Q, Zhang J, Xie Z, Deng Q, Li S, Wang S, Zhu J, Wang L, Liu H, Li P. 2013The evolution and pathogenic mechanisms of the rice sheath blight pathogen. Nature Communications 4, 1424. 